\title{
Capacidades tecnológicas y vínculos territoriales en empresas argentinas de maquinaria agrícola
}

\section{Silvina Mochi* (iD)}

* Universidad de Buenos Aires, Buenos Aires, Argentina

E-mail: silvinamochi@gmail.com

Recibido en: 08 Deciembre 2018 Revisado en: or Julio 2019 Acceptado o6 January 2020

\section{Resumen}

Las persistentes brechas tecnológicas de los países en desarrollo en un contexto de transición hacia nuevos paradigmas tecno-organizacionales, evidencian la necesidad de profundizar en el entendimiento sobre sus procesos de cambio tecnológico. En este marco, el objetivo del presente artículo es analizar el sendero de construcción de capacidades tecnológicas, productivas y organizacionales en empresas argentinas de maquinaria agrícola, a fin de desentrañar sus procesos de innovación y mecanismos de aprendizaje. Asimismo, se estudian los vínculos con los agentes territoriales, teniendo en cuenta el rol de las instituciones intermediarias. Desde un abordaje empírico, evolutivo y sistémico se realizó una investigación cualitativa que permitió demostrar la influencia de un conjunto de factores micro y meso, así como irregularidades, discontinuidades y diversidad de niveles y tipo de capacidades en las trayectorias de empresas industriales. De esta manera, el trabajo aporta elementos que contribuyen a los estudios evolucionistas sobre cambio tecnológico y desarrollo territorial, y a la reflexión en el diseño e implementación de instrumentos de políticas públicas.

Palabras Clave: Capacidades tecnológicas; Vínculos territoriales; Industria

Código JEL: O14, O32, O33 


\begin{abstract}
The persistent technological gaps of developing countries in a context of transition to new techno-organizational paradigms highlight the need to deepen understanding about their processes of technological change. In this framework, the objective of this article is to analyze the path of construction of technological, productive and organizational capacities in Argentine agricultural machinery companies, in order to unravel their innovation processes and learning mechanisms. Likewise, links with territorial agents are studied, taking into account the role of intermediary institutions. From an empirical, evolutionary and systemic approach, this qualitative research was carried out to demonstrate the influence of some micro and meso factors, as well as irregularities, discontinuities and diversity in the levels and type of capabilities in the trajectories of industrial companies. In this way, the paper provides elements that contribute to the evolutionist studies on technological change and territorial development, as well as to the reflection in the design and implementation of public policy instruments.
\end{abstract}

KeYwords: Technological capabilities; Territorial links; Industry

JEL CoDEs: O14, O32, O33 


\section{Introducción}

El cambio tecnológico es considerado uno de los factores dinámicos del crecimiento para diversas escuelas de pensamiento económico. Desde los años 1980 ha sido retomado por tratarse de uno de los principales elementos que explican las diferencias en el desarrollo de los países.

En este contexto, la literatura evolucionista pone especial énfasis en los estudios sobre innovación, considerada un fenómeno incremental, acumulativo y sistémico. Se entiende el cambio técnico como un proceso endógeno influenciado por factores históricos, económicos, sociales e institucionales que modelan los patrones de crecimiento y desarrollo (NELSON; WINTER, 1982). De esta manera, se busca abrir la "caja negra" para un mejor entendimiento de los senderos de aprendizaje, que dista de la concepción simplificada, aislada y exógena de la tecnología así como de su incorporación automática (LALL, 1992).

Desde esta perspectiva, se cuestiona la idea de países en desarrollo (PED) como receptores pasivos de las tecnologías generadas en los países desarrollados (PD) (BELL; PAVITT, 1993), y la falta de atención a las capacidades tecno-organizacionales requeridas para alcanzar innovaciones tendientes a reducir las brechas tecnológicas. En esta dirección, desde la década del años 1980 se han realizado algunas investigaciones para entender la dinámica tecnológica y la acumulación de capacidades de estos países. Dicha literatura revela trayectorias heterogéneas en su evolución, grado de complejidad y factores de influencia (DAHLMAN; WESTPHAL, 1982; DAHLMAN; ROSS-LARSEN; WESTPHAL , 1987; LALL, 1987, 1992; KATZ, 1984; BELL; PAVITT, 1995; entre otros).

Cabe decir que los estudios sobre innovación en PED han sido generalmente abordados desde un análisis estático y agregado, basado en encuestas y modelos econométricos, sumado a algunas investigaciones empíricas centradas en pocos casos, principalmente grandes empresas. Por la complejidad de estos procesos, diversos autores resaltan la necesidad de combinar el análisis cuantitativo y cualitativo (LÓPEZ, 2009; EDQUIST, 2014; DUTRENIT, 2004; KATZ, 1984). Otros sugieren ampliar la cantidad de casos de estudio (FIGUEREIDO, 2010) y relacionar el análisis de capacidades con el diseño de políticas de innovación (EDQUIST, 2014).

En este marco, se encuentran un conjunto de preocupaciones que dieron origen a este trabajo. Por un lado, las temáticas sobre capacidades, territorio y políticas se abordan generalmente de manera separada, lo que impide visualizar algunos factores explicativos de los fenómenos estudiados por cada "compartimento conceptual". 
Por otra parte, en países como Argentina, la estructura productiva se caracteriza por una elevada heterogeneidad regional y sectorial así como una alta concentración de las industrias en determinados polos y nodos geográficos relativamente más desarrollados. Frente a estas particularidades, los estudios con abordaje agregado y estático - a escala nacional y mismo sectorial-, que desatienden el análisis de las partes - sistemas regionales y territoriales-, pueden resultar insuficientes para una adecuada comprensión de los fenómenos aquí analizados. Por otra parte, si bien las investigaciones latinoamericanas sobre capacidades tecnológicas enfatizan la conectividad, en general se enfocan en empresas y realizan tangencialmente un abordaje cualitativo, integral e histórico contemplando las trayectorias de cambio tecnológico de las empresas, las instituciones, los agentes intermediarios y su relación con la dinámica del territorio.

Además, las políticas de innovación como mecanismos de incentivos son ocasionalmente abordadas en dichas investigaciones. Adicionalmente, en buena parte de los instrumentos diseñados en PED aún subyace la idea de linealidad e incorporación automática de las tecnologías, sin analizarse detalladamente las competencias de los sectores estratégicos en una cantidad representativa de empresas desde una mirada sistémica y de largo plazo.

Por tales razones, el objetivo del presente artículo es analizar el sendero de construcción de capacidades tecnológicas y de vinculación en empresas argentinas de maquinaria agrícola, en particular diez fabricantes de sembradoras, a fin de desentrañar sus procesos de innovación, sus mecanismos de aprendizaje y las relaciones con agentes del entorno. Basado en un enfoque territorial se enfatiza el rol de las instituciones intermediarias ya que pueden representar un factor determinante para la conectividad en los PED.

El trabajo se aborda desde un marco conceptual que combina el enfoque evolucionista sobre capacidades tecno-organizacionales junto con la literatura sobre desarrollo territorial. Como herramienta metodológica, se diseñó una matriz analítica que considera las taxonomías de Lall (1992), Bell y Pavitt (1995) y Dantas y Bell (2009, 2011) dado que posibilitan un análisis dinámico mediante gradientes de complejidad tecnológica que permiten desentrañar el ritmo, la dirección y los pasos atravesados en los procesos de innovación. Se agrega una dimensión sobre vínculos territoriales como nexo para estudiar las relaciones con el entorno y sus agentes.

La selección del sector de maquinaria agrícola se debe a que representa uno de los rubros de mayor dinamismo en la industria argentina, con un amplio recorrido histórico y altos niveles de innovación (BISANG; ANLLÓ; CAMPI, 2015). Su 
trayectoria se trazó en paralelo a la transformación del sector agrícola nacional, lo que explica su ubicación geográfica y los avances en la mecanización. Esto responde a la exigente y permanente demanda por parte de arrendatarios y contratistas, la experiencia acumulada bajo el modelo de sustitución de importaciones, la implementación de la siembra directa, los nuevos paquetes biotecnológicos, la concentración de la tierra y la expansión de la soja. Presenta, además, antecedentes en la conformación de cluster y polo industrial - de los pocos casos en el país-, con fuertes niveles de conectividad entre firmas, cámaras, proveedores y clientes, instituciones de ciencia y tecnología (CyT) y políticas públicas (LAVARELLO; SILVA; LANGARD, 2010) desde la década del años 1950, siendo beneficiarios de diversos instrumentos de financiación en los últimos 20 años.

Los problemas mencionados y particularidades nacionales, motivaron a abrir la "caja negra" con focalización en un sector estratégico de larga tradición que requiere aún de importantes esfuerzos público-privados para mejorar su posicionamiento competitivo a nivel internacional.

En efecto, desde un abordaje empírico este trabajo aporta un análisis evolutivo y sistémico en el marco de un estudio cualitativo de caso múltiple de diez empresas. A través de la matriz metodológica se profundiza en trayectorias de cambio tecnológico de largo plazo, incorporando no sólo los esfuerzos endógenos de las empresas (tecnológicas, producción e inversión) sino también su relación con la dinámica territorial, sus instituciones y agentes intermediarios. De esta manera, el trabajo brinda evidencias que aportan a los estudios micro y meso-económicos y de taxonomías del cambio tecnológico estableciendo puentes entre las diversas temáticas abordadas, desarrolladas desde diferentes enfoques. Además, contribuye a repensar el diseño de políticas dado que permite diferenciar los factores influyentes y patrones de comportamiento de las empresas, así como sus niveles y tipos de competencias. Se evita así reincidir en incentivos neutrales que pueden menoscabar su efectividad en la mejora de capacidades en países con amplias brechas intra y extra sectoriales y regionales.

El artículo se desarrolla de la siguiente manera. En primer lugar se expone el marco conceptual. En segundo lugar, se explica la metodología, la matriz analítica propuesta y el trabajo de campo realizado. A modo de contextualización se presentan brevemente las características del sector de maquinaria agrícola y el Cluster. Posteriormente, se muestran las evidencias empíricas que exhiben datos comparativos y describen las diferentes fases de construcción de capacidades tecnológicas y vínculos territoriales. Por último, se presentan las conclusiones con algunas recomendaciones de políticas. 


\section{Marco conceptual}

La literatura evolucionista del cambio tecnológico se centra en una perspectiva holística, histórica y multifacética, y considera la innovación como un fenómeno evolutivo y sistémico. Se trata, además, de un proceso de aprendizaje interactivo en el que se relacionan organizaciones (empresas e instituciones) heterogéneas para complementar sus saberes, lo que permite combinar el aprender haciendo con el aprender usando (LUNDVALL, 1992; FREEMAN; PÉREZ, 1988).

En este marco surgen los conceptos de sistema sectorial (MALERBA; ORSENIGO, 2000) y territorial de innovación. Desde una visión multidimensional el enfoque territorial enfatiza en los factores endógenos, el entorno productivo e institucional, las reglas y acuerdos, y el comportamiento y competencias de los actores locales, que resultan condicionantes para la generación y difusión de conocimientos (VÁZQUEZ BARQUERO, 2011). Los enfoques de redes organizacionales de conocimientos se complementan con dichas teorías, junto con la vasta literatura centrada en los distritos industriales y clusters.

Los PED evidencian rasgos específicos en sus procesos de innovación y sistemas. Habitualmente se realizan innovaciones mediantes mejoras incrementales basadas en trayectorias tecnológicas previamente desarrolladas por los PD y la I+D formal explica sólo una parte de estos procesos (BARLETTA; ROBERT; YOGUEL, 2012). Generalmente tienen una marcada demanda externa de ciencia y tecnología (CyT), lo que debilita la generación de competencias propias. Por otro lado, las crisis macroeconómicas y políticas contrapuestas se han traducido en obstáculos para la conformación de sistemas de innovación consolidados, de espacios de aprendizaje interactivo y trayectorias tecnológicas estables (AROCENA; SUTZ, 2001; DUTRÉNIT; ARZA, 2015).

\subsection{Las capacidades bajo el enfoque sistémico de la innovación}

La literatura evolucionista ha puesto especial atención en el análisis de las capacidades tecnológicas y los mecanismos de aprendizaje de las organizaciones y sistemas. Bajo diferentes denominaciones, resaltan la importancia de las habilidades para absorber conocimientos del ambiente, así como su uso efectivo para transformar o crear nuevas tecnologías y responder a los cambios del entorno (COHEN; LEVINTHAL, 1990; TEECE; PISANO, 1994). La elección y desarrollo de tecnologías por parte de las empresas no es automática sino el resultado de esfuerzos de selección y adaptación 
que necesitan de un umbral determinado de conocimientos codificables y tácitos previos (LALL, 1992). Éstos se generan a partir de las rutinas y experiencias colectivas de I+D, gestión, producción y comercialización (NELSON; WINTER, 1982). De esta manera, se va determinando la trayectoria tecnológica de las empresas, lo que da cuenta del carácter evolutivo y path dependence de los procesos de aprendizaje.

En esta línea, las investigaciones en los PED han estado inspiradas en la corriente evolucionista. Los aportes de Dahlman y Westphal (1982), Dahlman, Ross-Larsen y Westphal (1987), Lall (1987) y Katz (1984) fueron adoptados como base para los trabajos estructurados en taxonomías tales como las propuestas por Lall (1992); Bell y Pavitt (1995) y Dantas y Bell (2009, 2011), que contribuyeron a desentrañar los procesos de conformación de capacidades de manera dinámica y a lo largo del tiempo. De las dos primeras se destaca la diferenciación entre actividades tecnológicas, de producción y de inversión, considerándose importante observar los cambios en los procesos productivos, organizacionales y de gestión (toma de decisiones, proyectos y proyecciones), ya que pueden impactar en las innovaciones y la definición de estrategias.

Dantas y Bell $(2009,2011)$ se centran en las redes de conocimiento, tanto en sus propiedades, sus fuentes y la dirección de los flujos de intercambio cognitivo. Proponen cuatro gradientes: asimilación, adaptación, generación y estratégicas. Las actividades de asimilación se refieren a las habilidades de operacionalización y uso de tecnologías existentes, a partir de tareas rutinarias y saberes tácitos, con escasos vínculos extra-firma y mecanismos de aprendizaje pasivos. Las capacidades de adaptación se relacionan a las mejoras y adecuación, con esfuerzos de absorción y diseño que permiten cambios relativamente incrementales. Las vinculaciones externas se orientan a la búsqueda de información, capacitación, asistencia técnica, búsqueda de diseño y ocasionalmente I+D. Las capacidades de generación consisten en las habilidades para crear cambios más sustanciales, mediante una mayor formalización de la I+D y capacidad para desarrollar nuevos productos y procesos, con conocimientos cercanos o al nivel de la frontera tecnológica internacional. Las relaciones externas se intensifican relativamente mediante actividades tecnológicas más sofisticadas de capacitación e intercambios para la I+D. Las capacidades estratégicas aportan mayor grado de novedad, basadas en equipos de $\mathrm{I}+\mathrm{D}$ formal para crear conocimientos básicos, disruptivos y estratégicos que compitan o superen

1 Desde un análisis estático en el marco de cluster, se encuentran los aportes de Bell y Albu (1999), Guiliani y Bell (2005) y Giuliani y Arza (2009), quienes consideran que las capacidades de absorción de las firmas explican las capacidades de vinculación, sin que el nivel meso incida por sí mismo en tales lazos. 
la frontera internacional de conocimiento en tecnologías existentes o nuevas, con vínculos externos más complejos y formalizados.

Basados en dichas taxonomías, se sucedieron otros estudios, algunos de ellos más enfocados en las diferencias de los senderos, los ritmos y las velocidades, con posibles disrupciones y discontinuidades (DUTRÉNIT, 2004) bajo un análisis empírico, enriquecidos por otros que aumentan la cantidad de casos de estudios (FIGUEIREDO, 2010). Dichos autores cuestionan la idea de continuidad y linealidad en los procesos de construcción de capacidades desde los estadios tempranos con bajos grados de complejidad hasta niveles más estratégicos, encontrando posibles restricciones e inestabilidades durante esa transición (DUTRENIT, 2004; FIGUEREIDO, 2010). En particular, Figuereido (2010) objeta la presunción de una sola vía de acumulación hasta alcanzar el nivel de "frontera" como un punto final que, contrariamente, considera como un horizonte fluido a explorar. Por su parte, Dantas y Bell $(2009,2011)$ demuestran que el proceso no es repetitivo ni necesariamente acumulativo ya que puede virar en una dirección negativa, lo cual limita la interacción de las empresas con agentes externos.

En paralelo, el enfoque evolucionista enfatiza las capacidades de vinculación. $\mathrm{Al}$ respecto, los estudios empíricos en PED demuestran el predominio de vínculos informales, raramente orientados a I+D. Las investigaciones de Argentina afirman una relación directa entre el desarrollo de vinculaciones y el nivel de las capacidades tecnológicas y organizacionales de las empresas (LAVARELLO; SILVA; LANGARD, 2010; ERBES; ROBERT; YOGUEL, 2010), con flujos de conocimiento bidireccionales en las firmas con competencias más elevadas, y mejoras incrementales y tecnologías blandas en aquellas de bajos niveles (BARLETTA; ROBERT; YOGUEL, 2012).

En este marco, los aspectos relacionados a las capacidades de gestión se encuentran tangencialmente analizados al interior de las empresas y en las instituciones de su entorno. En este sentido, la influencia de los agentes intermediarios en la generación de vínculos entre las organizaciones es raramente abordada en los estudios sobre capacidades. Entre la literatura orientada a este tema, se resalta su rol como intermediarios "sistémicos", ya que actúan como puentes entre empresas, instituciones de CyT y organismos gubernamentales (VAN LENTE et al., 2003; KLERKX; GILDEMACHER, 2012).

Como fue señalado inicialmente, los temas abordados en este trabajo quedan circunscriptos en un marco conceptual nutrido de diversos enfoques y campos de la literatura que comparten algunos pilares. Así, el anclaje territorial e institucional de 
los procesos de cambio tecnológico en el sector de la maquinaria agrícola-empresas y cluster-, permite desarrollar los puentes analíticos entre las evidencias empíricas y la teoría, desde una mirada sistémica y evolutiva.

\section{Aspectos metodológicos}

El presente artículo es el resultado de un trabajo de investigación previo que se basó en una metodología cualitativa ${ }^{2}$. Por la multiplicidad de factores influyentes en los procesos de innovación y las características de PED, esta metodología se considera más apropiada para captar en profundidad sus rasgos distintivos y pasos.

En particular, se adoptó un estudio de caso múltiple a fin de lograr conclusiones más "robustas" cuyas preguntas de investigación se basaron en el "cómo" y en el "por qué". Aplicando la lógica de la réplica y considerando cada caso como una unidad de análisis, éstas fueron seleccionados para predecir resultados similares (réplica literal) o bien contrastantes (réplica teórica) (YIN, 2003), lo cual permitió hacer una comparación entre las mismas.

Como fue indicado, se diseñó una matriz analítica cuyo contenido conjuga y adapta algunas dimensiones y categorías de las taxonomías citadas de modo de complementarlas. Se agregan los vínculos territoriales como una dimensión adicional, que aporta una perspectiva sistémica en la construcción de competencias hacia afuera de las empresas.

En efecto, la matriz incluye dos dimensiones: evolución de las capacidades tecnológicas y de los vínculos territoriales (Cuadro 1). La primera toma los cuatro niveles gradientes de evolución de capacidades tecnológicas propuestos por Dantas y Bell $(2009,2011)$ y las categorías de producción e inversión de Lall, Bell y Pavitt. La segunda considera las relaciones entre actores, tanto sus objetivos como la información o los conocimientos aportados o recibidos, y los intermediarios de dichos lazos.

Los gradientes quedan establecidos a partir de "hitos" de importancia en el sector en diferentes períodos de tiempo, representados por productos. El pasaje de un nivel a otro queda supeditado al nivel de complejidad de las capacidades requerido para cada producto. Dichos gradientes y categorías facilitan las respuestas al cómo y porqué los senderos pueden diferir entre las firmas y qué factores pueden afectar la continuidad y regularidad en su construcción.

2 Trabajo de investigación realizado en el marco de la tesis doctoral de la autora (MOCHI, 2017). 
CUADRO 1

Matriz analítica de capacidades tecnológicas y vínculos con otros agentes

\begin{tabular}{|c|c|c|c|}
\hline Dimensiones & \multicolumn{3}{|c|}{ Niveles de evolución de capacidades } \\
\hline $\begin{array}{c}\text { Cambio } \\
\text { tecnológico }\end{array}$ & Asimilación & Adaptación & Generación \\
\hline $\begin{array}{l}\text { Actividades tecno- } \\
\text { lógicas }\end{array}$ & $\begin{array}{l}\text { Uso y operacionalización } \\
\text { Reparaciones e imita- } \\
\text { ción. }\end{array}$ & $\begin{array}{l}\text { Ingeniería inversa, adap- } \\
\text { taciones. }\end{array}$ & $\begin{array}{l}\text { Ingeniería inversa, inno- } \\
\text { vaciones incrementales } \\
\text { cercanas o al nivel de la } \\
\text { frontera internacional. }\end{array}$ \\
\hline $\begin{array}{l}\text { Fuentes y dirección } \\
\text { del conocimiento }\end{array}$ & $\begin{array}{l}\text { Conocimiento materiali- } \\
\text { zado en equipos. Saberes } \\
\text { agronómicos de usuarios. }\end{array}$ & $\begin{array}{l}\text { Moderados desde pro- } \\
\text { veedores, instituciones } \\
\text { CyT, competidores. } \\
\text { Avance conocimientos } \\
\text { internos. }\end{array}$ & $\begin{array}{l}\text { Ampliación fuentes ex- } \\
\text { ternas. Consolidación } \\
\text { conocimientos endó- } \\
\text { genos. }\end{array}$ \\
\hline \multicolumn{4}{|l|}{$\begin{array}{l}\text { Actividades de } \\
\text { inversión }\end{array}$} \\
\hline $\begin{array}{l}\text { Toma de decisiones, } \\
\text { gestión de proyectos } \\
\text { y proyecciones }\end{array}$ & $\begin{array}{l}\text { Monitoreo pasivo, nula } \\
\text { planificación. Toma de } \\
\text { decisión centralizada en } \\
\text { dueños. }\end{array}$ & $\begin{array}{l}\text { Avances relativos en mo- } \\
\text { nitoreos, procesos de } \\
\text { selección simples, plani- } \\
\text { ficación. }\end{array}$ & $\begin{array}{l}\text { Avances en análisis de } \\
\text { prefactibilidad, plani- } \\
\text { ficación, selección de } \\
\text { tecnologías. Descentra- } \\
\text { lización relativa en toma } \\
\text { de decisiones. }\end{array}$ \\
\hline \multicolumn{4}{|l|}{$\begin{array}{l}\text { Actividades de } \\
\text { producción }\end{array}$} \\
\hline $\begin{array}{l}\text { Procesos y } \\
\text { organización de } \\
\text { la producción. }\end{array}$ & $\begin{array}{l}\text { Procesos rudimentarios. } \\
\text { División de tareas inci- } \\
\text { piente. }\end{array}$ & $\begin{array}{l}\text { Mejoras relativas en or- } \\
\text { ganización de procesos } \\
\text { y trabajo. Transición a } \\
\text { sistema semi-industrial. }\end{array}$ & $\begin{array}{l}\text { Procesos industrializa- } \\
\text { dos, mayor complejidad } \\
\text { y coordinación orga- } \\
\text { nizacional. Monitoreo } \\
\text { calidad, productividad } \\
\text { y costos. Profesionali- } \\
\text { zación Infraestructura, } \\
\text { equipamiento, TIC }\end{array}$ \\
\hline \multicolumn{4}{|l|}{$\begin{array}{l}\text { Vínculos } \\
\text { territoriales }\end{array}$} \\
\hline $\begin{array}{l}\text { Tipo y objetivos del } \\
\text { vínculo }\end{array}$ & $\begin{array}{l}\text { Generalmente informal, } \\
\text { con clientes Intercambio } \\
\text { de conocimientos agro- } \\
\text { nómicos. }\end{array}$ & $\begin{array}{l}\text { Vínculos formales e in- } \\
\text { formales (clientes, menor } \\
\text { en proveedores, institu- } \\
\text { ciones CyT) Objetivos: } \\
\text { asistencia técnica, infor- } \\
\text { mación, conocimientos } \\
\text { agronómicos. }\end{array}$ & $\begin{array}{l}\text { Idem anterior, avances en } \\
\text { formalidad. Objetivos: } \\
\text { asistencia técnica, infor- } \\
\text { mación e I+D. Transfe- } \\
\text { rencia tecnológica }\end{array}$ \\
\hline
\end{tabular}

Fuente: Elaboración propia en base a Lall (1992), Bell y Pavitt (1995) y Dantas y Bell (2009, 2011). 
Durante la investigación se combinaron diversas fuentes de información secundarias y primarias, que implicaron la revisión de estudios, informes y documentos del sector, la información de páginas web, folletos y la asistencia a eventos. Complementariamente se realizaron entrevistas en profundidad con informantes clave de las empresas, el sector agrícola (clientes), instituciones y organismos gubernamentales ${ }^{3}$. Su selección se basó en las recomendaciones de referentes que aportaron a la diversidad de visiones y permitieron alcanzar la saturación teórica.

Los casos de estudio están localizados en las provincias de Santa Fe, Córdoba y Buenos Aires (Mapa 1). El criterio de selección de las empresas incluye el tamaño, la representación en el mercado local, el nivel de innovación, la pertenencia al cluster CECMA y haber sido beneficiaria de financiamiento público dirigido a innovación. Se combinaron empresas grandes, medianas y pequeñas: las dos firmas argentinas más grandes, que representan el $40 \%$ de las ventas nacionales internas; y dos empresas medianas que alcanzan otro $20 \%$, destacadas por su liderazgo. Adicionalmente, se incluyeron dos de mediano tamaño y cuatro más pequeñas, que suman alrededor del 25\% del mercado, identificadas algunas de ellas como "seguidoras" en innovaciones. Dos de las diez firmas -la más grande y una de las pequeñas (localizada en provincia de Buenos Aires)- se encuentran fuera del cluster CECMA y no solicitaron financiamiento al Ministerio de Ciencia, Tecnología e Innovación Productiva (MINCyT) de Argentina.

\section{El sector de la maquinaria agrícola en Argentina}

El sector está integrado por unas 850 empresas, fundamentalmente PyMEs de capital nacional, sumado a 290 agropartistas y más de 20 firmas nacionales de agricultura de precisión, que se concentran principalmente en las provincias de Santa Fe, Córdoba y Buenos Aires (47\%, 30\% y 20\% respectivamente). En particular, el rubro de sembradoras cuenta con más de 60 fabricantes, cuyas ventas son predominantemente locales y la mayor producción se concentra en menos de 10 firmas (ARGENTINA, 2016).

En su estructura se diferencian dos grupos: empresas nacionales de larga trayectoria de sembradoras directas, tolvas, embolsadoras y pulverizadoras, aglomeradas bajo el formato de clusters; y, empresas multinacionales líderes en el mercado de

3 Se realizaron 32 entrevistas a empresas (a referentes con larga trayectoria; en las de mayor porte se acudió a gerentes de diferentes áreas) y 21 entrevistas a referentes institucionales, académicos y gubernamentales entre marzo de 2015 y febrero de 2017, cuya duración osciló entre 45 y 75 minutos. Para ello se utilizaron cuestionarios semi-estructurados. 
cosechadoras y tractores, insertadas en las cadenas globales de valor (LAVARELLO, SILVA; LANGARD, 2010). Sin embargo, en el segundo grupo los productos son fundamentalmente importados, generando un fuerte déficit comercial externo que se ha vuelto estructural.

\subsection{El Cluster Empresarial CIDETER de la Maquinaria Agrícola (CECMA)}

El aglomerado se encuentra ubicado en las localidades del departamento Belgrano (Provincia de Santa Fe) y Marcos Juárez (Provincia de Córdoba) ${ }^{4}$, donde se aglutinan 557 empresas que representan el 65\% del total nacional (Mapa 1).

Como antecedentes institucionales se destacan la creación de la Dirección de Asesoramiento Técnico (DAT) en 1975, y la Escuela de Educación Técnica de las Parejas en los '80, que han ofrecido asesoramiento y formación técnica. Los Centros Industriales también se han dedicado al asesoramiento comercial y capacitaciones.

En el año 1998 se creó la Fundación Centro de Investigación y Desarrollo Tecnológico Regional (CIDETER) en Las Parejas, que representa la unidad de vinculación tecnológica (UVT), ofreciendo asesoramiento técnico, formulación y gestión de proyectos tecnológicos, cursos y organización de eventos. Se han puesto en marcha proyectos asociativos mediante acuerdos de producción, de comercialización, de compras y capacitaciones 5 , muchos de ellos financiados desde organismos públicos tales como el Fondo Tecnológico Argentino (FONTAR), la Secretaría de la Pequeña y Mediana Empresa y Desarrollo Regional (SEPyME), el Consejo Federal de Ciencia y Técnica (COFECyT) y el Consejo Federal de Inversiones (CFI).

Otro hito a resaltar es la creación del Cluster Empresarial CIDETER de la Maquinaria Agrícola (CECMA) en 2006, en el marco de un proyecto público-privado mediante financiamiento público (FONTAR), cuya coordinación estuvo a cargo de la Fundación CIDETER ${ }^{6}$. El siguiente hito destacado fue la construcción del primer Centro Regional Tecnológico en 2010, mediante una acción de integración público-privada, en el cual se desarrollan actividades diversas (capacitación, investigación, laboratorios, biblioteca, servicios tecnológicos).

4 El nodo central nuclea 275 empresas en las localidades de Las Parejas (48\%), Armstrong (31\%), Marcos Juárez (13\%) y Las Rosas (8\%).

5 Conforme los datos aportados por dicha Fundación, ésta asiste a 557 firmas. Entre 2011 y 2015 se gestionaron 244 proyectos financiados por MINCyT y 189 mediante otros organismos, totalizando US \$30,9 y US \$ 5,7 millones, respectivamente. Registra 40 convenios con instituciones nacionales e internacionales, se resalta el acuerdo con el Centro MECCANO (Italia).

6 Los integrantes son: Instituto Nacional de Tecnología Agropecuaria (INTA) y de Tecnología Industrial (INTI), Universidad Nacional de Rosario, Universidad Tecnológica Nacional, DAT, Consejo Nacional de Investigaciones Científicas y Tecnológicas (CONICET), Instituto Argentino de Soldadura (IAS), organismos públicos de Santa Fe y Córdoba, Municipios de Las Parejas, Las Rosas, Amstrong y Marcos Juárez y centros industriales, ProArgentina, Agencia ProCórdoba y gobiernos provinciales. 
MAPA 1

Mapa de Argentina. Ubicación de Cluster CECMA y empresas

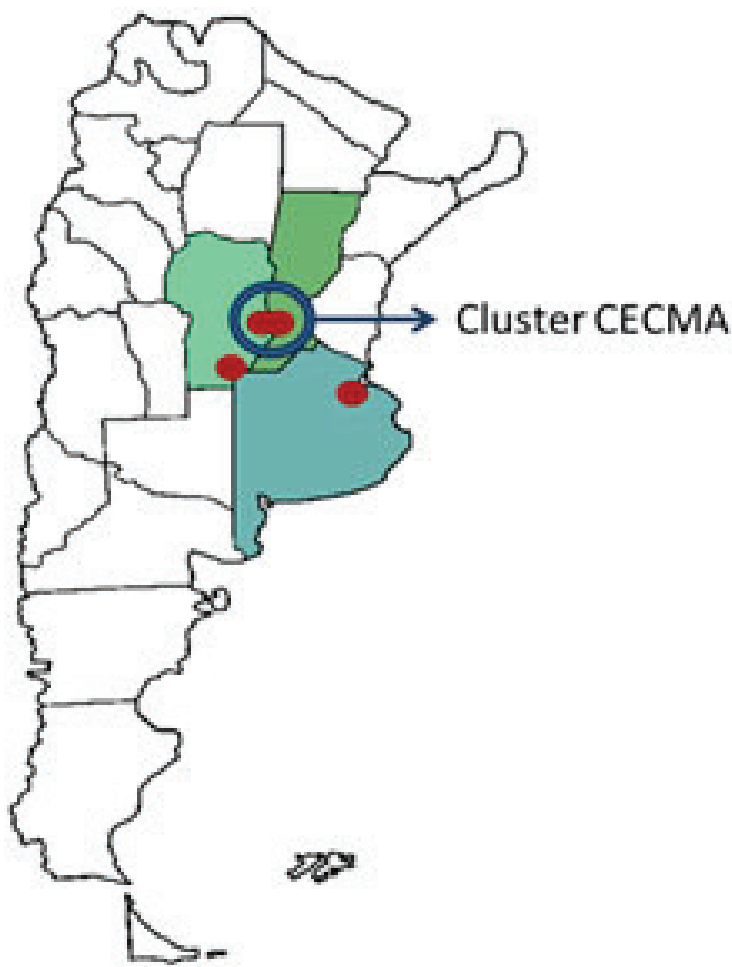

Nota: Los puntos indican ubicación de casos de estudios

\section{Evidencias empíricas de la investigación}

Como resultado del análisis se identificaron tres fases de construcción de capacidades tecnológicas atravesadas por las empresas:

- Capacidades tecnológicas de asimilación. Décadas del 1950 y 1960

- Capacidades tecnológicas de adaptación. Década del 1960 al 1980

- Capacidades tecnológicas de generación. Década del 1980 hasta 2016

Previo a exponer dichas etapas se presentan sintéticamente algunos datos generales de los casos de estudio: 
CUADRO 2

Características de las empresas - ańo 2017

\begin{tabular}{|l|l|l|l|c|c|c|c|}
\hline Datos & $\begin{array}{l}\text { Año } \\
\text { de crea- } \\
\text { ción }\end{array}$ & Localidad & $\begin{array}{l}\text { Provin- } \\
\text { cia }\end{array}$ & $\begin{array}{c}\text { Cantidad } \\
\text { emple- } \\
\text { ados }\end{array}$ & $\begin{array}{c}\text { Participaci- } \\
\text { ón mercado } \\
\text { Nacional } \\
\text { (\%) }\end{array}$ & $\begin{array}{c}\text { Super- } \\
\text { ficie (m2) }\end{array}$ & $\begin{array}{l}\text { Integrante } \\
\text { de Cluster } \\
\text { CECMA }\end{array}$ \\
\hline $\begin{array}{l}\text { Empresa A } \\
\text { (EA) }\end{array}$ & 1953 & $\begin{array}{l}\text { M o n t e } \\
\text { Maíz }\end{array}$ & Córdoba & 340 & $20 / 22$ & 25.000 & No \\
\hline $\begin{array}{l}\text { Empresa B } \\
\text { (EB) }\end{array}$ & 1956 & Armstrong & Santa Fe & 130 & $20 / 22$ & 20.000 & $\mathrm{Si}$ \\
\hline $\begin{array}{l}\text { Empresa C } \\
\text { (EC) }\end{array}$ & 1957 & Las Parejas & Santa Fe & 220 & 9 & 17.000 & $\mathrm{Si}$ \\
\hline $\begin{array}{l}\text { Empresa D } \\
(\mathrm{ED})\end{array}$ & 1957 & Las Parejas & Santa Fe & 120 & $5 / 6$ & 14.000 & $\mathrm{Si}$ \\
\hline $\begin{array}{l}\text { Empresa E } \\
\text { (EE) }\end{array}$ & 1958 & Fuentes & Santa Fe & 105 & $6 / 7$ & 10.000 & $\mathrm{Si}$ \\
\hline $\begin{array}{l}\text { Empresa F } \\
\text { (EF) }\end{array}$ & 1960 & Las Parejas & Santa Fe & 35 & 5 & 5.000 & $\mathrm{Si}$ \\
\hline $\begin{array}{l}\text { Empresa G } \\
(\mathrm{EG})\end{array}$ & 1976 & Armstrong & Santa Fe & 40 & 5 & 3.500 & $\mathrm{Si}$ \\
\hline $\begin{array}{l}\text { Empresa H } \\
(\mathrm{EH})\end{array}$ & 1978 & Armstrong & Santa Fe & 50 & 5 & 8.000 & $\mathrm{Si}$ \\
\hline $\begin{array}{l}\text { Empresa I } \\
(\mathrm{EI})\end{array}$ & 1977 & Armstrong & Santa Fe & 100 & 9 & 10.000 & $\mathrm{Si}$ \\
\hline $\begin{array}{l}\text { Empresa J } \\
(\mathrm{EJ})\end{array}$ & 1980 & $\begin{array}{l}\text { Carmen de } \\
\text { Areco }\end{array}$ & $\begin{array}{l}\text { Buenos } \\
\text { Aires }\end{array}$ & 50 & 2 & 2.200 & $\mathrm{No}$ \\
\hline
\end{tabular}

Fuente: elaboración propia

Es posible diferenciar dos etapas fundacionales de las empresas. Por un lado, un grupo pionero comprendido entre los ańos 1953 y 1960, y por otro, un grupo contemporáneo que abarca desde 1976 hasta 1980 (Cuadro 2). La modalidad de conformación varía de un caso a otro, en ocasiones familias relacionadas a la actividad agrícola, o mediante grupos de emprendedores que generalmente contaban con experiencia previa.

El Cuadro 3 detalla los hitos-productos adoptados como parámetros de cambios para cada fase en el sector de sembradoras.

CUADRO 3

Productos-hitos por etapa de acumulación de capacidades tecnológicas

\begin{tabular}{|l|l|l|}
\hline \multirow{2}{*}{ Productos/Fases } & \multicolumn{2}{|c|}{ Fases } \\
\cline { 2 - 3 } Productos & \multicolumn{1}{|c|}{ Asimilación } & \multicolumn{1}{c|}{ Adaptación } \\
\hline Reparaciones, equipos de labranza. & $\begin{array}{l}\text { Sembradoras convencionales, equipos } \\
\text { de labranza vertical. }\end{array}$ \\
\hline
\end{tabular}

Fuente: elaboración propia 
Desde los primeros años se encuentran algunas diferencias en la duración de las fases, que difícilmente pueden atribuirse a un solo factor, ya que se conjugan aspectos tales como el espíritu emprendedor de los dueños o empleados a cargo de los desarrollos tecnológicos, los mecanismos de aprendizaje utilizados, los vínculos externos establecidos, las exigencias del mercado, las inversiones y las estrategias encaradas, entre otros. Además, la conducta innovativa de los empresarios varía en intensidad según las etapas, sin ser necesariamente continua o creciente. En esta línea, el Gráfico 1 y el Esquema 11 ilustran, respectivamente, la cantidad de ańos atravesados por cada empresa en dichas fases y los liderazgos en el lanzamiento de productos.

\section{GRÁFICO 1}

Duración de cada fase de acumulación de capacidades tecnológicas (en años)

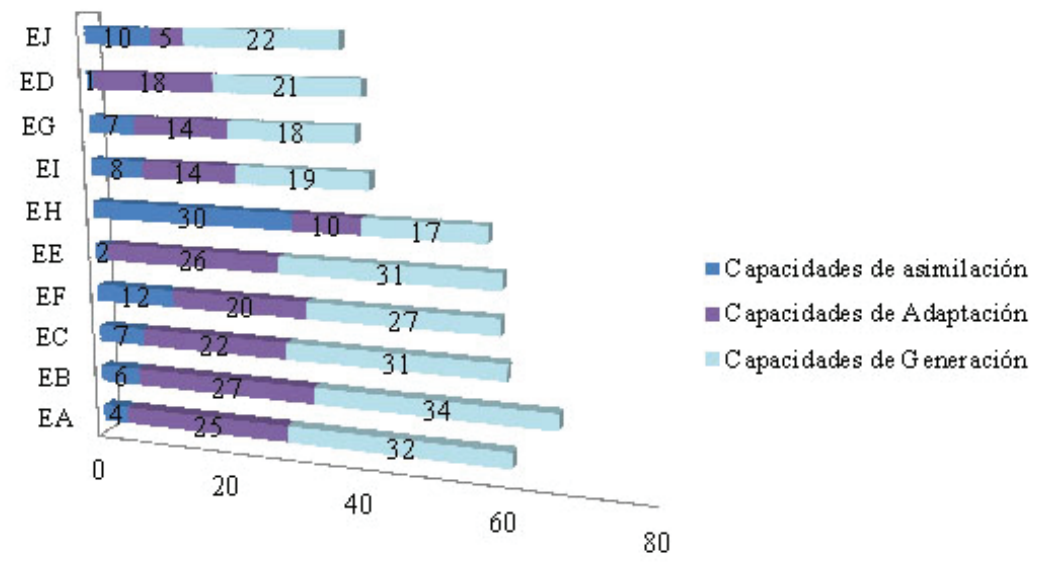

Fuente: Elaboración propia

El gráfico precedente (Gráfico No2) evidencia que la totalidad de las firmas atravesaron experiencias de asimilación, cuya duración tiene un promedio de 7 años, con la excepción de una empresa que se mantuvo 30 años en esta fase. La etapa de adaptación, en cambio, supera en general los 20 años. En el grupo contemporáneo la cantidad de ańos de adaptación fue menor debido al advenimiento de la siembra directa. Hasta esta instancia las firmas fabricaban implementos (no sembradoras) con la excepción de ED que avanzaba en mejoras incrementales sobre las sembradoras convencionales, tras los casos pioneros. La fase de generación está delimitada por los equipos para siembra directa, que representaron el punto de inflexión ante la 
necesidad de realizar desarrollos endógenos para aplicarlos localmente. Adicionalmente, la agricultura de precisión incorporó componentes electrónicos y las TICs en las máquinas.

Respecto de los productos, el Esquema 1 refleja que las empresas que lideraron el mercado nacional en equipos de labranza y sembradoras desde la década del '50, en general, aún conservan este rasgo. Del grupo contemporáneo algunas lograron equipararse o superar a las primeras en términos de innovaciones nacionales. En todos los casos comenzaron con los equipos de labranza, algunos avanzaron con sembradoras convencionales mientras que las empresas más pequeñas continuaron con aquellos productos hasta la consolidación de la siembra directa.

Hasta la introducción de la agricultura de precisión, se observan rasgos similares a los anteriores productos, sin embargo, en el segmento de sembradoras Air Drill7 aparecen primeramente otras empresas precursoras. Casos como EJ se posicionan tecnológicamente con esta gama de equipos desde 1996, mientras que la competencia pionera se insertó 18 años después. No obstante, las empresas líderes nacionales han retomado recientemente su carrera en las tecnologías Air Planter.

Conforme Lim y Lee (2001) es posible identificar más de un modo de catch up en los casos de estudio. EB marcó su liderazgo en innovaciones nacionales desde su creación diferenciándose en algunos mecanismos de aprendizaje, mientras que otras empresas de menor porte fueron originalmente "seguidoras", incluso dos de las firmas pioneras innovadoras desaceleraron su ritmo durante varios años. Algunas empresas contemporáneas han seguido el camino adoptado por sus antecesoras, en tanto que EJ apostó a innovar en otro segmento antes que sus pares; destacándose también ED por sus saltos en su trayectoria tecnológica previo a sus pares coetáneas. En particular, EF siguió su propio camino con otra línea de productos por fuera de las sembradoras -una retroexcavadora-, como un primer paso a la diversificación. Por otra parte, EH, EI y EG permanecieron en el mercado de equipos de labranza en un lapso relativamente mayor de tiempo sin necesariamente desaparecer del mercado, acelerando más recientemente sus desarrollos para poder competir. Es decir, los horizontes perseguidos difieren en el tiempo y metas.

Además de estos aspectos es importante señalar algunas similitudes y diferencias en sus trayectorias, para lo cual se considera pertinente explayarse en los mecanismos de aprendizaje (Cuadro No4).

7 Los insumos se trasladan a la sembradora por aire, mediante mangueras. 


\section{ESQUEMA 1}

Lanzamiento de productos por empresa - Período 1950-2016

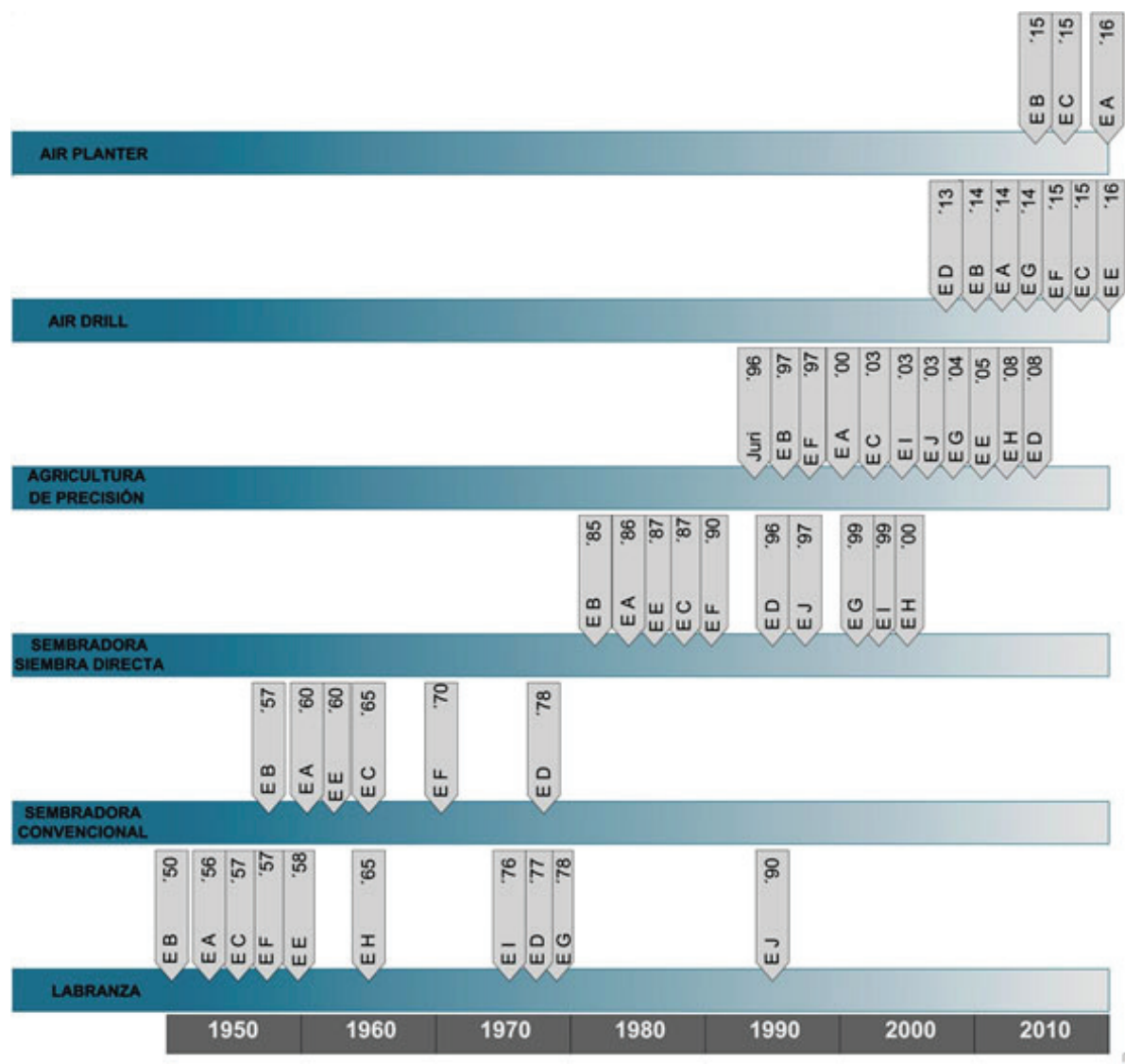

Fuente: Elaboración propia

Las áreas de desarrollo fueron creadas luego de 30 años -en promedio- desde la fundación en el grupo pionero, con las excepciones de EB y EH -22 y 50 años, respectivamente-. En las empresas contemporáneas, las oficinas se instalaron a lo largo de la década del '00, y la cantidad de años transcurridos ronda en los 26 años (Cuadro 4). Por otra parte, la estructura de gastos en recursos humanos es variable, las empresas más grandes tienen equipos de alrededor de 10 personas entre profesionales y técnicos, siendo menor en los demás casos. 
CUADRO 4

Mecanismos de aprendizaje

\begin{tabular}{|c|c|c|}
\hline $\begin{array}{l}\text { Tipo de } \\
\text { mecanismo de } \\
\text { aprendizaje }\end{array}$ & Mecanismos de aprendizaje & $\begin{array}{l}\text { Aplicación en los } \\
\text { casos de estudio }\end{array}$ \\
\hline \multirow[t]{7}{*}{ Internos } & Capacitaciones técnicas & Todas las empresas \\
\hline & $\begin{array}{l}\text { Creación de área técnica y de desarrollo de } \\
\text { productos }\end{array}$ & $\begin{array}{l}\text { Todas las empresas. EA } \\
\text { (1986); EB (1975); EC (1985); } \\
\text { EF (1985); EE (1992); EH } \\
\text { (2010); EI (2005); EG (2003); } \\
\text { ED ('90/2003); EJ ( } \\
2006)\end{array}$ \\
\hline & $\begin{array}{l}\text { Reuniones formales y programadas entre áreas } \\
\text { para analizar experiencias, productos, otros. }\end{array}$ & $\begin{array}{l}\text { Toma de decisiones centrada } \\
\text { principalmente en los dueños. } \\
\text { Pocas empresas adoptan reuniones } \\
\text { de Directorio para discutir sobre } \\
\text { innovación. } \\
\text { Intercambio de información } \\
\text { y conocimiento entre áreas } \\
\text { predominantemente informal. }\end{array}$ \\
\hline & $\begin{array}{l}\text { Comunicación formal interna mediante } \\
\text { seminarios, memorias, gacetilla, informes } \\
\text { internos. }\end{array}$ & $\begin{array}{l}\text { No se identifican. Redacción de } \\
\text { informes de reuniones: empresas } \\
\text { más grandes (2010). }\end{array}$ \\
\hline & $\begin{array}{l}\text { Uso de herramientas de gestión (software) } \\
\text { para diseño y desarrollo de productos } \\
\text { (planimetría) }\end{array}$ & $\begin{array}{l}\text { Todas las empresas. EA } \\
\text { (1995); EB (1992/1995); EC } \\
\text { (1995); EF (1996); EE (1996); } \\
\text { EH (2007); EI (2006); EG } \\
\text { (2005); ED (1995); EJ (2006) }\end{array}$ \\
\hline & Certificación de normas de calidad (ISO) & $\begin{array}{l}\text { EB y EF (2007) / ED (2011) / } \\
\text { EJ (2012) }\end{array}$ \\
\hline & $\begin{array}{l}\text { Codificación: redacción de técnicas de } \\
\text { productos y procedimientos (archivos, } \\
\text { carpetas, dibujos, planos) }\end{array}$ & $\begin{array}{l}\text { Carpetas y archivos en EB ('75). } \\
\text { Registros mediante sistemas de } \\
\text { software de diseño: todas las } \\
\text { empresas }\end{array}$ \\
\hline \multirow[t]{4}{*}{ Externos } & Visitas y asistencia a clientes & Todas las empresas \\
\hline & $\begin{array}{l}\text { Monitoreo a competidores nacionales e } \\
\text { internacionales (observación, viajes, ferias, } \\
\text { exposiciones) }\end{array}$ & $\begin{array}{l}\text { Todas las empresas } \\
\text { Viajes al exterior: EB ('65), } \\
\text { EA, EC, EE y EF ('70) y ED } \\
\text { ('92), EJ ('99). EG, EH, EI } \\
\text { (ocasionalmente a países de } \\
\text { exportación) }\end{array}$ \\
\hline & $\begin{array}{l}\text { Búsqueda de conocimientos /información en } \\
\text { internet, congresos, bases de patentes, revistas } \\
\text { y libros. }\end{array}$ & $\begin{array}{l}\text { Sólo búsquedas en internet y } \\
\text { folletos en algunas empresas }\end{array}$ \\
\hline & $\begin{array}{l}\text { Búsqueda de información en instituciones de } \\
\text { CyT }\end{array}$ & $\begin{array}{l}\text { Todas las empresas (empresas } \\
\text { líderes en mayor medida) }\end{array}$ \\
\hline
\end{tabular}


CUADRO 4

Mecanismos de aprendizaje

\begin{tabular}{|c|c|c|}
\hline \multirow[t]{9}{*}{ Externos } & $\begin{array}{l}\text { Asistencia técnica y servicios tecnológicos de } \\
\text { instituciones de CyT }\end{array}$ & Todas las empresas \\
\hline & $\begin{array}{l}\text { Cursos de capacitación técnica en } \\
\text { instituciones/empresas }\end{array}$ & Todas las empresas \\
\hline & Contratación de profesionales, expertos & Algunas empresas \\
\hline & $\begin{array}{l}\text { Intercambio de recursos humanos con otras } \\
\text { empresas extranjeras (práctica laboral) }\end{array}$ & EB \\
\hline & $\mathrm{I}+\mathrm{D}$ con competidores & $\begin{array}{l}\text { EB ('00) / EA, EC, EE, EI y ED } \\
(' 05)\end{array}$ \\
\hline & $\mathrm{I}+\mathrm{D}$ con proveedores & $\begin{array}{l}\text { EB ('65) / EA, EC, EE, EI y ED } \\
(' 05)\end{array}$ \\
\hline & $\mathrm{I}+\mathrm{D}$ con instituciones de CyT & $\begin{array}{l}\text { EB ('70), EC ('88), EA y EC } \\
(' 10)\end{array}$ \\
\hline & Acuerdos de transferencia tecnológica & $\begin{array}{l}\text { EB ('70), EC ('88), EA y EC } \\
(' 10)\end{array}$ \\
\hline & $\begin{array}{l}\text { Alianzas y acuerdos de licenciamiento con } \\
\text { otras empresas }\end{array}$ & EB ('66) \\
\hline
\end{tabular}

Fuente: Elaboración propia en base a Dutrenit (2001) y bibliografía citada.

Por lo expuesto hasta aquí, se observa que las empresas han atravesado secuencialmente diferentes niveles de capacidades tecnológicas, pasando inicialmente por habilidades menores hasta alcanzar otras de mayor complejidad, lo que queda plasmado en el tipo de productos desarrollados. Sin embargo, dichos senderos difieren en tiempos y mecanismos de aprendizaje adoptados, lo cual representa factores que explican parcialmente algunas de las diferencias. Estos hallazgos permiten acercarse a similares conclusiones de los trabajos citados de Katz, Dutrénit y Figueiredo, en cuanto a la idea de gradualidad que no necesariamente avanzan en idéntica dirección y celeridad. Inclusive, algunos senderos se estancan durante determinado período, es decir, no son progresivos, lo que puede interpretarse como un aspecto contradictorio desde la perspectiva evolucionista.

La siguiente sección brinda mayor detalle de los pasos y sucesos atravesados por las empresas en las diferentes etapas de acumulación de capacidades tecnológicas. 


\subsection{Las etapas de acumulación de capacidades tecnológicas, de producción y vinculación}

\subsubsection{Gestación de las capacidades durante los años 1950 y 1960}

Hasta la década del 1950 los implementos agrícolas provenían en su mayoría de Estados Unidos. Las restricciones externas para la compra, sumado a la tradicional afición al trabajo agrario cotidiano, se identifican como los primeros disparadores que impulsaron el inicio de una etapa de reparaciones de máquinas usadas, que dio origen a varias empresas. Otras surgieron de ex empleados de la empresa Funcas, la primera en instalarse en Las Parejas.

Por lo tanto, el conocimiento de frontera tecnológica se originaba en empresas extranjeras especializadas en máquinas para grandes extensiones de tierras. Los usuarios y talleres locales tomaban conocimiento de las tecnologías haciendo reparaciones, desarmando los equipos y usándolos, bajo métodos de prueba y error. Los mecanismos de aprendizaje utilizados eran la observación, el uso y la operacionalización, conforme las demandas de clientes del sector agrícola pampeano. Se trataba de canales rudimentarios de transmisión de saberes tácitos y de forma unilateral. Estas actividades estaban supeditadas a la experiencia del empresario-dueño o, en algunos casos, disponían de trabajadores de oficio autodidactas dotados de capacidad creativa. En efecto, se observan un conjunto de actividades que se condicen con la fase de asimilación expuesta en la taxonomía propuesta, en la cual se establecen las primeras rutinas para adquirir conocimientos (NELSON; WINTER, 1982) mediante mecanismos de aprendizaje coincidentes con la idea de "aprender haciendo y usando" (LUNDVALL, 1992).

Los emprendimientos se instalaron originariamente en los hogares de los dueños, definidos en las entrevistas como "grandes herrerías". Las actividades de producción se basaban en procesos elementales y fuertemente experimentales, casi nulos en rutinas, con tareas pautados diariamente conforme la demanda. En las empresas pioneras, el principal obstáculo en los años 1950 y 1960 era la compra de materias primas, y en efecto el material se recuperaba de máquinas añejas, sin hábitos en la previsión de abastecimiento de insumos.

Los fabricantes se relacionaban casi exclusivamente con sus clientes -los productores o contratistas agrícolas- quienes representaban un informante clave para los ajustes y mejoras menores, transmitiendo paralelamente los saberes de su labor. De esta manera, la dupla fabricante-clientes permitía complementar los conocimientos mecánico y agronómicos, que no obstante eran poco sofisticados, fueron de carácter 
bidireccional desde el principio, lo cual se repite en las firmas creadas en los años 1970. Es decir, la relación productor-usuario fue determinante desde sus inicios (LUNDVALL, 1992).

Por su estrecha relación con el sector agrícola, las empresas nacieron en el área urbana de localidades pequeñas, con infraestructura deficiente, tanto en instalaciones eléctricas y comunicaciones como en el acceso a los grandes centros comerciales del país. Las instituciones técnicas locales se limitaban a entidades educativas de nivel secundario y técnico.

\subsubsection{Mejoras incrementales a partir de adaptaciones entre los años 1960 y 1980. Incorporación de nuevas empresas}

En este período las empresas pioneras atravesaron la fase de adaptación en sus capacidades tecnológicas, en tanto que el grupo de firmas contemporáneas se encontraba en un momento de asimilación, con mecanismos de aprendizaje equivalentes a sus antecesoras. Los prototipos se basaban fundamentalmente en productos de firmas multinacionales líderes - John Deere como principal referente- mediante la imitación e ingeniería inversa con mejoras incrementales moderadas para responder a los requerimientos de los usuarios argentinos. En particular, el acercamiento a Estados Unidos como "espejo" tecnológico se explica por las similitudes en extensiones de tierras. En coincidencia con los estudios citados sobre PED, las innovaciones de este segmento industrial se han realizado históricamente mediante mejoras incrementales basadas en tecnologías previamente desarrolladas por los PD. El crecimiento de la demanda, la producción y la competencia nacional pusieron de cara la importancia de realizar viajes y asistir a exposiciones de las tecnologías de vanguardia, como canal para captar nuevas ideas. Las visitas a otras regiones se hicieron habituales como mecanismo de búsqueda de nuevos clientes y flujo de información sobre sus solicitudes. Asimismo, las ferias internacionales posibilitaron contactarse con especialista académicos, algunos de los cuales fueron contratados para diversas actividades de asesoramiento, capacitaciones y relevamientos en el cluster.

Durante la investigación se resaltó el rol de los productores y los contratistas argentinos por su conocimiento en los equipos. Además, las demandas tecnológicas se intensificaron a partir de los viajes al exterior realizados por los clientes mejor posicionados económicamente, despertándoles nuevas exigencias. Esto incidió en las fuentes de conocimiento de los fabricantes ya que previamente no todos seguían con tanto rigor los adelantos norteamericanos. 
Los avances paulatinos en la complejidad tecnológica de los productos impulsaron a las empresas pioneras en innovación a crear áreas específicas de desarrollo y diseño desde la década del años1980. De esta manera se "jerarquizó" la sección imponiendo una separación más nítida entre las actividades de desarrollo y las tareas de producción (BELL; PAVITT, 1993).

Además, el incremento gradual de competidores nacionales representó cierta amenaza a las empresas existentes, generando en casos como EA, EB, EC y EE una mayor preocupación por innovar y diferenciarse a nivel nacional, logrando incluso el patentamiento de productos. ED era una empresa relativamente joven pero tuvo una actitud dinámica desde los años 1980. En general, las empresas se refirieron al trabajo "a medida del cliente", más acentuadamente en las empresas de menor porte que adoptaron como estrategia la atención más personalizada.

En coincidencia con la taxonomía metodológica, esta etapa se centró en la adaptación mediante el mecanismo de la imitación pero con mayores esfuerzos para responder a las exigencias del cliente local. En este sentido, es clave relacionar las dimensiones "cambio tecnológico" y "vínculos territoriales", ya que la demanda de dichos agentes representa un factor determinante para explicar el comportamiento de los empresarios. No obstante, queda reflejado que las empresas pioneras en innovación apuntaron a mecanismos de aprendizaje más sofisticados desde etapas tempranas, resaltándose el caso EA con contratos de transferencia y apertura temprana de su oficina de desarrollo. Esto explica en cierta medida la heterogeneidad en los senderos de las unidades estudiadas.

\section{Capacidades de producción}

El crecimiento comercial obligó a las empresas a ampliar su infraestructura o trasladarse fuera del área urbana y de los parques industriales. Las firmas pioneras de mayor tamaño avanzaron gradualmente en las rutinas de producción, aunque sin planificación y escasa visión de largo plazo. No obstante, los años 1970 representan un primer salto organizacional para EA, EB, EE y EF, delineando nuevas formas de organización y lay out, aunque primaba todavía la producción de tipo artesanal, que modestamente fue abasteciéndose de ciertas herramientas relativamente más sofisticadas. Se resalta que el viraje en las políticas económicas desde 1976 y su consecuente crisis frenaron las inversiones en bienes de capital e infraestructura, además de afectar el plantel del personal. Estos hechos explican algunas interrupciones en las trayectorias de las empresas, identificándose un mayor impacto en las actividades de producción e inversión. 
La información relativa a las demandas del mercado provenía de las áreas o personal encargado de ventas, o bien de los técnicos que hacían pruebas a campo, fluyendo de manera informal, carente de herramientas para su sistematización. Raramente accedían a medios publicitarios, la práctica habitual de difusión de los productos era del tipo "de boca en boca". Tampoco establecían registros escritos de las técnicas de desarrollo ni de producción, las empresas generaban sus prototipos en base al conocimiento tácito, supeditados a los ajustes -pruebas y ensayos- que se realizaban en la post-venta, con las excepciones de EB y EE.

Hasta aquí se evidencia que, contrariamente al modelo lineal de innovación, el segmento de sembradoras transita sus primeras fases de construcción de capacidades sin contar con áreas específicas de I+D ni conocimientos codificados. Por el contrario, la relación fabricante-cliente ha sido determinante para el intercambio de saberes y las mejoras incrementales adoptadas por los empresarios (LUNDVALL, 1992).

\section{Vínculos territoriales}

Las relaciones de las empresas continuaron fundamentalmente ligadas a los clientes. En paralelo, se tomó contacto con los competidores externos mediante viajes y asistencia a exposiciones (las firmas más grandes). Por otra parte, surgieron paulatinamente nuevos proveedores locales e internacionales.

A nivel institucional, comienza la relación con entidades de CyT, específicamente con la DAT y el INTA (años 1970). La primera representó el espacio para capacitaciones y asesoramiento técnico. En el caso de las universidades, sólo las empresas más grandes mencionaron vinculaciones para ensayos a campo y asesoramiento técnico y agronómico (Universidades Nacionales de Córdoba y Rosario).

La creación del parque industrial de Las Parejas (años 1970) representa un avance, junto con los centros industriales donde se dialogaba sobre aspectos comerciales y fiscales. Por otra parte, se crearon establecimientos educativos técnicos con especialidades orientadas a la mecánica. Las localidades fueron mejorando el acceso a las grandes ciudades. La llegada de la electricidad fue un progreso importante, sin embargo, en materia de comunicaciones aún atravesaban retrasos.

\subsubsection{Creación y consolidación de las capacidades de generación desde mediados de los años 1980 y el año 2016}

Los primeros avances hacia las habilidades para la generación de tecnologías se lograron a partir de la implementación de la siembra directa. Su mecanización se 
inspiró en sembradoras desarrolladas por Estados Unidos, en colaboración estrecha con representantes de John Deere y Great Plains. Posteriormente, la inserción de la agricultura de precisión y del segmento Air Drill atravesó similares recorridos. Sin embargo, desde la implementación del nuevo sistema agrícola, las empresas tuvieron que realizar esfuerzos adicionales en ingeniería, componentes y funciones debido a la necesidad de traducir otros conceptos de procesos agrícolas en la mecánica de las máquinas. Esto reclamó la comprensión de nuevos conocimientos tecnológicos dando lugar a innovaciones incrementales aunque supeditados a las firmas precursoras globales. Para ello se basaron en mecanismos de aprendizaje similares a la fase anterior aunque dotados de mayor grado de complejidad de conocimientos tanto tecnológicos como agronómicos.

La acumulación de capacidades endógenas permitió a las empresas llegar al nivel de la frontera tecnológica internacional en este segmento específico. De las entrevistas se desprende que el punto de inflexión y principal salto se logró en el 2000, ascendiendo a lo que podrían denominarse "capacidades de generación consolidadas", que posicionó a las sembradoras directas al nivel de las multinacionales. Incluso, se señaló que el tamaño y características de las empresas no marcan una brecha tecnológica significativa en el mercado nacional de sembradoras directas (en determinados productos), la diferencia está delimitada por la capacidad de producción y escala, las redes de comercialización, la facturación y los recursos para I+D y marketing. Asimismo, el advenimiento de la agricultura de precisión exigió la compatibilización entre los conceptos mecánicos y los electrónicos, planteando un cambio en la relación con los proveedores nacionales e internacionales.

La intensificación de las actividades tecnológicas indujo a las empresas más pequeñas a crear áreas técnicas específicas y enfatizar la diferenciación vía innovación o mejoras incrementales, como una estrategia para afrontar la candente competencia. Por su parte, las firmas precursoras locales destacaron el mayor empeño puesto en los desarrollo tecnológicos propios, los viajes sirven como disparadores de ideas pero comienzan a buscar la forma de "despegar", aunque reconocen que los conocimientos disruptivos se generan en las empresas multinacionales líderes.

En efecto, en línea con Bell y Pavitt (1993) se observa que a lo largo de la trayectoria de las empresas, todas necesitaron separar las actividades de producción y de desarrollo. Esto fue posible porque habían acumulado determinado umbral de capacidades tecnológicas que las habilitó para enfocarse en la $\mathrm{I}+\mathrm{D}$, bajo rutinas, recursos y equipamiento específicos, además de una mayor dotación de tiempo y personal idóneo. Cabe hacer una salvedad en las empresas que permanecen un 
largo período en la fase de adaptación (incluso de asimilación). En éstas se observa que, a pesar de haber acumulado habilidades suficientes para continuar a la etapa siguiente, el factor determinante fue la implementación de la siembra directa, y en consecuencia las crecientes exigencias de los clientes agrícolas. Por lo tanto, la $\mathrm{I}+\mathrm{D}$ formal explica más recientemente sólo una parte de estos procesos de innovación (BARLETTA; ROBERT; YOGUEL, 2012), en tanto que las firmas han realizado innovaciones incrementales mediante diferentes mecanismos informales (la interacción con los usuarios, por ejemplo).

Por otro lado, no obstante reconocerse los avances hacia la frontera internacional, las empresas no han alcanzado aún las capacidades de tipo "estratégicas". Algunos especialistas explicaron que la investigación básica es relativamente menor en este sub-sector, con la excepción de Estados Unidos, cuyas actividades derivan luego en investigación aplicada. Adicionalmente, indicaron que las universidades extranjeras contribuyen en información y estudios puntuales pero las compañías multinacionales trabajan "puertas adentro".

$\mathrm{Al}$ respecto, se entiende que el sector de sembradoras nacional se enfrenta a determinadas barreras tales como: falta de escala, grandes distancias a mercados globales, tamaño de empresas y escasos recursos destinados a investigación. Surgen entonces algunos interrogantes sobre las posibilidades de superar la frontera internacional estrictamente en este rubro y, por ende, si todas las empresas pueden alcanzar la cuarta fase de la matriz analítica. Esto refuerza la idea senderos tecnológicos como procesos no-lineales con diferentes horizontes a seguir (FIGUEREIDO, 2010).

A su vez, los fabricantes nacionales han estado tradicionalmente enfocados en la región pampeana y en efecto las sembradoras responden a la extensión y características de sus tierras y sus cultivos predominantes. Sin embargo, la inserción al mercado externo desde 2002 exigió adaptaciones además de recaudos para la logística, el cumplimiento de normas de calidad y la adecuación de las plantas fabriles. En paralelo, ante la significativa competencia y los vaivenes del mercado, se identifica una incipiente diversificación -en tamaño de máquina y tipo de cultivo (arroz, quinua, guar y chía)-, que implicaron sólo tareas de adaptación sin estrategias de largo plazo. Nuevamente se observa que el progreso técnico del segmento de este segmento está supeditado a las exigencias del mercado, con escasos incentivos para adoptar una estrategia de diversificación desde la oferta.

Frente a estos cambios, la participación en ferias internacionales se implementó como una práctica frecuente, realizándose en comitivas organizadas por cámaras empresariales y organismos públicos. Asimismo, se incrementaron las exposiciones 
nacionales desde la década del '90. Estos eventos son utilizados como espacios de encuentro entre fabricantes, clientes y proveedores así como medios de publicidad de los nuevos modelos de máquinas que representan, además, un canal para observar los productos de la competencia local.

Por lo tanto, las habilidades se fueron generando a partir de rutinas que se basaron principalmente en la resolución de problemas y exigencias del cliente, que fueron cambiando ante el surgimiento de nuevas demandas, lo que derivó en cambios posteriores de dichas rutinas y el desarrollo de innovaciones incrementales (NELSON; WINTER,1982). De esta manera, se constituyeron los cimientos para avanzar en las estructuras internas con diversos grados de complejidad de las innovaciones incrementales y responder a los cambios del entorno y contexto. La ingeniería inversa a partir de las tecnologías foráneas implicó esfuerzos y conocimientos adicionales para las adaptaciones y desarrollos endógenos, lo cual dista de la idea de transmisión inmediata de tecnología y conocimientos explícitos (LALL, 1992; BELL; PAVITT, 1993). Los senderos reflejan un alto contenido de desarrollo experimental, basados en conocimientos tácitos adquiridos mediante el uso y la interacción con otros agentes (LUNDVALL, 1992; FREEMAN; PEREZ, 1988), con ciertos avances en la codificación y formalización de las actividades de $\mathrm{I}+\mathrm{D}$, principalmente en las empresas de mayor porte. Además, quedan nuevamente de manifiesto algunas disrupciones y diferencias en los senderos de las empresas, explicados por los mecanismos de aprendizaje, grados de innovación, competencias y los efectos de factores externos.

\section{Los saltos en las capacidades de producción e inversión}

Esta fase representa un hito en términos de modernización y expansión de los procesos productivos. A pesar de los avances en desarrollos de productos, la organización industrial y las tecnologías de procesos estuvieron rezagadas hasta finales de los años 1990 y principios del años 2000. Estos cambios se identificaron en todos los casos de estudio, con diferencias en el momento de su realización y recursos aportados. De hecho, la profunda crisis económica argentina del año 2001 provocó la brusca caída de las ventas, el desuso de instalaciones y el despido de personal, lo cual frenó las inversiones y los desarrollos de prototipos8. En efecto, dichos problemas de contexto afectaron la continuidad del proceso de construcción de capacidades, paralizando todas o algunas actividades, dependiendo del caso.

8 En EA, por ejemplo, provocó la caída de convenios con empresas extranjeras destinados al desarrollo de nuevos productos, lo cual fue seńalado en las entrevistas como un factor determinante en el retraso de desarrollos posteriores. 
Esta etapa estuvo acompañada por cambios de rutinas y lay out, con mayor atención en la calidad y el cumplimiento de normativas, implementando normas ISO en ciertos casos y asesoramiento específico en otros. Se pusieron en marcha programas de capacitaciones desde los años 1990 organizados por la DAT y luego la Fundación CIDETER, con la colaboración del gobierno de la provincia de Santa Fe y organismos españoles.

En igual dirección, se ampliaron las plantas fabriles con importantes inversiones en equipamiento. La principal expansión se observa en las firmas de mayor tamaño, con avances significativos en la automatización con tecnologías de punta, la búsqueda de optimización de recursos, una mayor dedicación en la evaluación y selección de tecnologías, la dirección de procesos y la gestión de compras. En las demás empresas también se han logrado mejoras significativas.

En general, se incorporaron robots de soldadura, tornos de control numérico, máquinas de corte y prensas con PLC, puentes grúas, láser y plasmas de alta definición (las más grandes en mayor medida). También se adquirieron sistemas de software para la sistematización de la información y codificación dando lugar a la programación y la gestión de compras y ventas, facilitando la organización y registros, y la conexión intra-áreas. Desde la década del años 2000 se han mejorado los procesos de armado, terminación y soldaduras, así como las cabinas de secado y pintura, generalmente con asesoramiento de instituciones de CyT.

No obstante dichos avances, persisten las dificultades para la planificación estratégica de largo plazo y la carencia de herramientas específicas de las disciplinas relacionadas a inteligencia competitiva y prospectiva tecnológica. En general, las decisiones se toman cotidianamente, basadas en la intuición, las demandas del cliente, las ventas pasadas, las expectativas y la coyuntura económica productiva. En este sentido, quedó de manifiesto la necesidad de un cambio cultural en el gerenciamiento y la profesionalización.

Los resultados empíricos reflejan nuevamente un proceso gradual, sin embargo, se evidencia el desfasaje en las categorías de capacidades tecnológicas ya que, en paralelo a la creación de capacidades de generación, se mantenían grados inferiores para las actividades organizacionales, de producción e inversión, lo cual fue equiparándose más recientemente. Considerando las taxonomías de Lall (1992) y Bell y Pavitt (1995) es posible pensar que los diferentes niveles de acumulación cuentan con categorías que no necesariamente avanzan en paralelo, ya que están atravesados por un conjunto de factores que pueden influir de modo diverso. Es decir, las taxonomías sirven como soporte para analizar la evolución de los diferentes 
tipos de actividades sin restringirse a la $\mathrm{I}+\mathrm{D}$, no obstante, en ellas se presume cierta linealidad en el evolución de las diferentes dimensiones y sus categorías. Contrariamente, los casos de estudio demuestran una diversidad de situaciones que afectan la retroalimentación de las distintas competencias.

\section{Consolidación de la red de vinculaciones}

El actor más preponderado continuó siendo el cliente -productores y contratistasagregándose los pools de siembra y las asociaciones de productores como AAPRESID y AACREA9. En la primera se explicó que cuanto más innovador es el productor, más exige al proveedor de equipos, lo cual incide de manera directa en el grado de novedad o mejoras incrementales de los prototipos.

Por otra parte, los proveedores de agricultura de precisión paulatinamente se fueron vinculando con sus clientes, primero a través del productor y más recientemente de manera directa jugando un rol preponderante en la difusión de productos electrónicos y las TICs.

Los avances impulsaron los vínculos con otras empresas e instituciones de CyT. Se trató de una instancia de adaptación mutua a las necesidades privadas-privadas y público-privadas, que ha crecido en volumen y sofisticación10.

El INTA fue recurrentemente mencionado por sus aportes en conocimientos agronómicos y de agricultura de precisión, con actividades de extensión y colaboración en las pruebas y ajustes de equipos. La vinculación fue avanzando de manera gradual, alcanzando actualmente a la mayor parte del segmento. El Instituto es receptor y fuente de información de los fabricantes acerca de las tendencias tecnológicas y amenazas del mercado, que se transmiten mediante presentaciones, en el marco de ferias y reuniones periódicamente realizadas en conjunto con el Centro Tecnológico CIDETER.

Es importante resaltar el rol de la Fundación CIDETER como “intermediaria sistémica" en la creación y fortalecimiento de los vínculos entre empresas, instituciones de CyT y organismos gubernamentales, con una participación activa en los acuerdos. Los empresarios destacaron su contribución en las relaciones extra-firma, las actividades técnico-productivas y la gestión de proyectos, identificándose como el espacio de encuentro.

9 Asociación Argentina de Productores en Siembra Directa; Asociación Argentina de Consorcios Regionales de Experimentación Agrícola

10 Se destacan algunos antecedentes como la creación de la empresa PROASO S.A. (2005), integrada por 15 empresas y 20 proveedores para crear una cosechadora axial de alta tecnología; el Proyecto 315 conformado por 3 empresas de CECMA para sembradoras con idénticos componentes. Dos proyectos de investigación aplicada: uno encabezado por EA, INTA y UNR, para desarrollo de un monitor universal; el otro ejecutado por EC, UTN y IAS, para optimizar los procesos de soldaduras. 
Por otro lado, se deduce que los empresarios sólo "absorben" la información y conocimientos, ya que el intercambio entre ellos queda supeditado a aspectos comerciales, fiscales, recursos humanos o eventualmente procesos productivos. En este sentido, no se identificó un lugar donde debatan sobre innovación ni estrategias sectoriales. La progresiva competencia y los riegos de la "imitación" los vuelve reticentes a sociabilizar sus saberes. Tampoco se han creado actividades académicas o sectoriales en formato de seminarios o congresos.

Por lo tanto, la red de interrelaciones se fue ampliando e intensificando paulatinamente, con el intercambio de conocimiento de tipo unidireccional y bidireccional, lo cual se condice en general con los pasos de la taxonomía metodológica. Sin embargo, la intensidad y complejidad de las relaciones así como sus objetivos difieren en los casos de estudios. A modo de ejemplo, no todas las empresas establecen vínculos orientados a la $\mathrm{I}+\mathrm{D}$ a pesar de contar con capacidades de generación (Esquemas 2 y 3).

\section{ESQUEMA 2}

\section{Evolución de las capacidades tecnológicas y de vinculación}

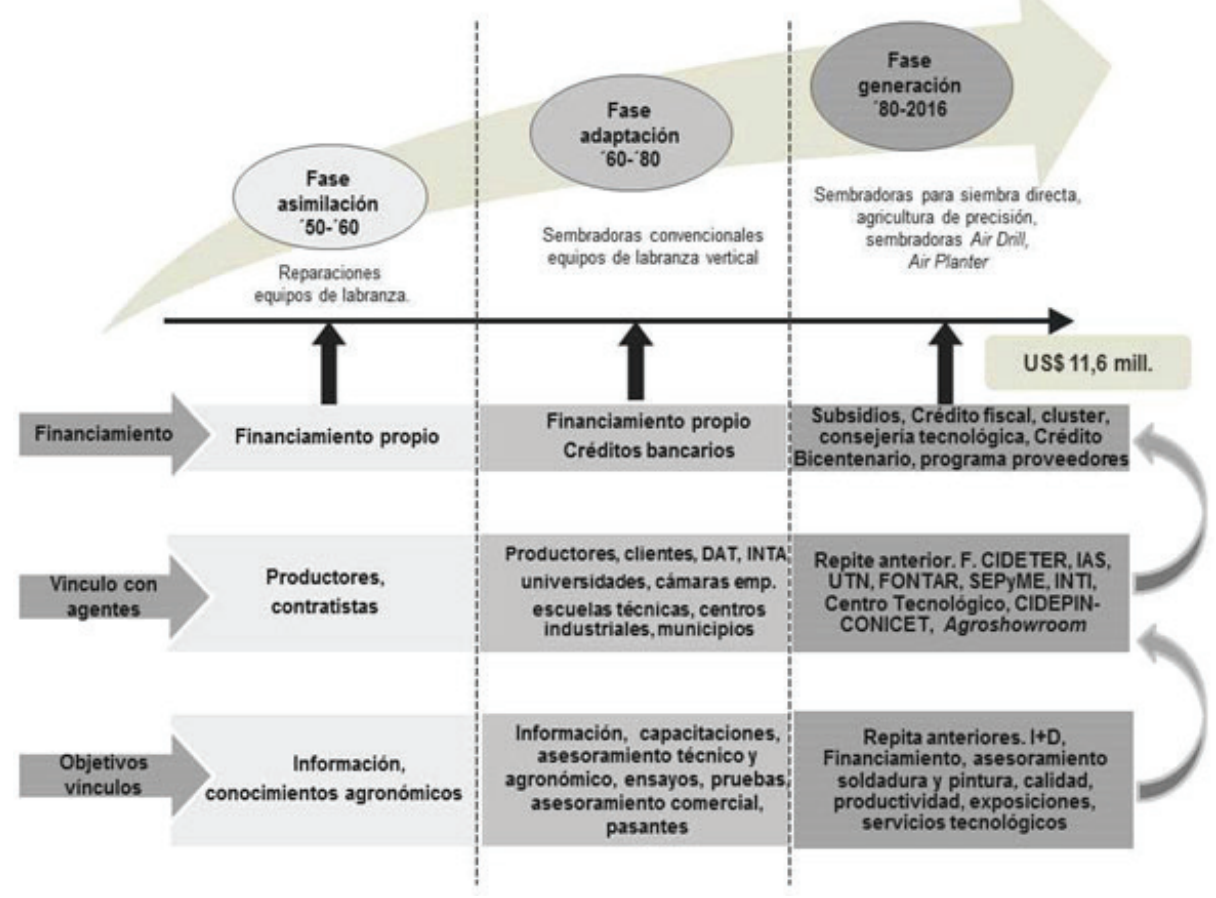

Fuente: elaboración propia 
ESQUEMA 3

Vínculos entre las empresas y agentes externos. Flujos de conocimientos e información

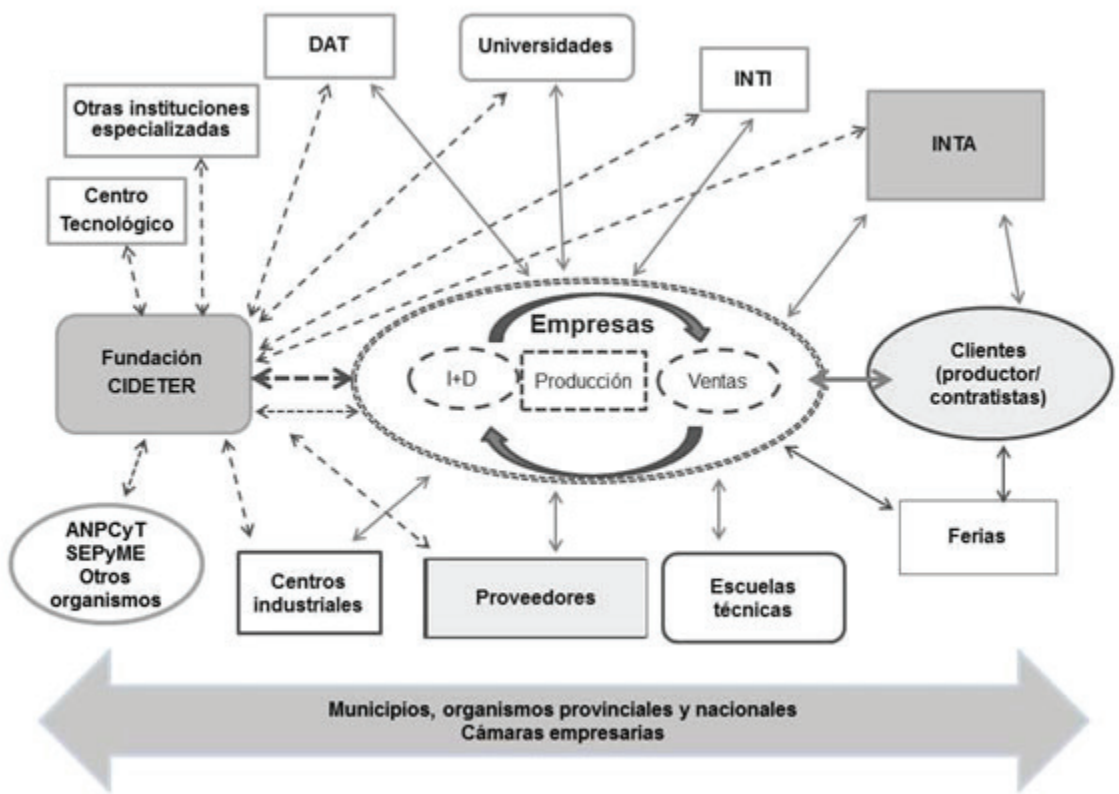

Fuente: Elaboración propia. Notas: las líneas punteadas indican contactos a través de instituciones intermediarias. Líneas lisas indican contactos directos.

Asimismo, de la investigación se desprende que las capacidades de vinculación no han estado exclusivamente supeditadas a las capacidades tecnológicas. En coincidencia con los estudios argentinos citados previamente, es posible encontrar una relación directa y restrictiva entre capacidades de innovación y vinculación con fines de I+D (principalmente en la fase de generación). Sin embargo, la influencia de actores como la Fundación CIDETER y el INTA fue determinante para lograr los nexos entre los actores territoriales (para actividades de $\mathrm{I}+\mathrm{D}$, productivas, organizacionales), siendo condicionantes aspectos como la confianza y reputación. Es decir, las capacidades de vinculación tampoco fueron adquiridas automáticamente ni han dependido únicamente de las competencias en I+D. En efecto, en el marco de las taxonomías, se considera necesario analizar la posible incidencia de los agentes intermediarios del entorno, para un mejor entendimiento de la conformación y evolución de las redes de conocimientos y productivas en los territorios.

Respecto del entorno, se observa un mayor apoyo de los municipios sumado a las mejoras en accesos y comunicaciones. Sin embargo, se encuentran falencias en la formación técnica sumado a la lejanía a las universidades, que dificulta la capta- 
ción de recursos humanos, con énfasis en los mandos medios y altos. La reticencia de muchos profesionales para instalarse en esas poblaciones se debe también a las carencias en la calidad de las prestaciones de servicios de salud, educativos y culturales. Estos obstáculos se tornan estructuralmente contradictorios con el crecimiento industrial, lo cual despierta algunos interrogantes respecto del alcance competitivo si no se armoniza con el desarrollo territorial.

\section{Conclusiones}

En un contexto de cambios de paradigmas tecno-organizacionales y persistentes brechas tecnológicas se considera necesario continuar realizando estudios sobre las características del cambio tecnológico en los PED para repensar las estrategias que permitan mitigar los problemas y afrontar los actuales desafíos.

Las evidencias empíricas demuestran que los procesos de innovación en las empresas argentinas de sembradoras han sido producto de un proceso sistémico, interactivo y path dependence, con una significativa interrelación con los clientes, lo cual refuerza los aportes evolucionistas citados. Las capacidades tecnológicas fueron incorporándose gradualmente sobre la base de diferentes mecanismos de aprendizaje y mejoras incrementales que permitieron alcanzar el nivel de la frontera tecnológica internacional.

Sin embargo, en coincidencia con Katz (1984), Dutrénit (2004) y Figueiredo (2010), queda reflejada la inexistencia de un sendero único de construcción de dichas competencias, que dan cuenta de las posibles discontinuidades, irregularidades y diferentes velocidades en los procesos atravesados, las cuales son acumulativas pero no necesariamente progresivas ya que a veces se estancan o, incluso, retroceden. A su vez, en complemento al trabajo de Figueiredo (2010), se observa que los horizontes perseguidos difieren en tiempos y metas, además de dilucidarse la posibilidad de llegar a un "techo" en las capacidades que permite alcanzar la frontera tecnológica internacional sin alcanzar aún capacidades estratégicas.

Por otra parte, de las estructuras de taxonomías propuestas por los autores citados subyace cierta idea de homogeneidad y evolución progresiva en los cambios hacia adentro de las dimensiones y categorías de cada fase. Contrariamente, este trabajo revela avances disímiles en tales compartimentos demostrando que las deficiencias en capacidades de producción e inversión, aun contando con capacidades de innovación, pueden traducirse en obstáculos para alcanzar las competencias estratégicas. 
A su vez, de la investigación se desprende que la interacción de las empresas con actores territoriales ha sido condicionante para el desarrollo de determinadas capacidades de conectividad. Se resaltan aquí las instituciones intermediarias, que han sido legitimadas por los empresarios para la difusión y socialización de los conocimientos y la información, la facilitación de vínculos públicos-privados y privado-privados y el acceso al financiamiento público, canalizando recursos "desde arriba" hacia los territorios en un sector específico. La conformación de redes no fue automática ni espontaneo necesariamente, sino que implicó un proceso de construcción de capacidades en las instituciones en el que influyeron aspectos tales como la confianza, la legitimidad, la reputación y otros de índole cultural. En este sentido, las capacidades de vinculación no sólo dependen de las capacidades de I+D sino también de otros factores de incidencia y de capacidades de gestión tanto a nivel de las firmas como del territorio, lo que permiten entender la naturaleza de tales redes. En efecto, por las características de los sistemas de innovación de los PED, la institucionalización de la intermediación desde un abordaje territorial se considera clave para la transformación tecnológica-productiva.

En síntesis, a partir de esta investigación cualitativa basada en un estudio de caso múltiple de diez empresas se contribuye a la literatura evolucionista y de desarrollo territorial complementando el análisis de diferentes tipos de capacidades -tecnológicas, producción, gestión y vinculación- en relación con la participación de instituciones y agentes intermediarios en la facilitación de lazos y la conformación de redes en los sistemas territoriales. En este marco, se refuerzan las objeciones a la concepción lineal y simplificada de los procesos de innovación en tanto que la acumulación de capacidades y su escalamiento a mayores niveles de complejidad representa un requisito fundamental para afrontar los problemas asociados a las brechas tecno-organizacionales y productivas.

Adicionalmente este trabajo aporta un marco conceptual que conjuga diversos enfoques y campos de la literatura, lo cuales son generalmente tratados de manera separada. A partir de la matriz metodológica diseñada fue posible establecer los puentes entre las evidencias empíricas y la teoría centrándose en las trayectorias de cambio tecnológico en relación con la dinámica territorial e institucional desde una perspectiva sistémica y de largo plazo. En estructuras productivas de las características de Argentina, el abordaje analítico y metodológico de esta investigación se considera un aporte dado que escapa de la lógica de estudios agregados y estáticos, que resultan insuficientes para abrir la "caja negra" de los procesos mencionados. 
Por lo expuesto, queda de manifiesto que la aplicación de políticas neutrales y horizontales puede ser deficiente para mitigar las diferencias con PD. En tal sentido, estos estudios sirven para diferenciar las empresas según su tipo y niveles de competencias e identificar las instituciones de CyT e intermediarias para fomentar los vínculos entre agentes, incluyendo las características territoriales en el análisis. Por lo tanto, se torna necesario reflexionar sobre el diseño e implementación de instrumentos de políticas públicas en sectores estratégicos tendientes a responder a las especificidades de las empresas, instituciones, sectores y sistemas territoriales. Dada las diferencias en capacidades tecnológicas, productivas, de gestión y vinculación, y considerando el carácter gradual en los procesos de innovación se vuelve necesario un ordenamiento y clasificación por tipo de beneficiarios y tipo de competencias incorporadas así como instrumentos. Estos últimos pueden pensarse en escalas que van desde herramientas blandas a otras de mayor complejidad -individuales o asociativas- que apalanquen innovaciones incrementales y saltos tecnológicos a nivel sectorial, así como mejoras en la productividad y competencias estratégicas. Asimismo, cabría retomar la discusión sobre fondos sectoriales basados en recursos soberanos que contemplen el rediseño y/o creación de centros e institutos tecnológicos con anclaje territorial, dotados de grupos de gestión y de $\mathrm{I}+\mathrm{D}$ formados y estables.

En este marco, es pertinente incluir en el debate los desafíos en torno al desarrollo de capacidades estratégicas y planificación; la diversificación y complementación con otras tecnologías -TIC, inteligencia artificial (I4.0), por ejemplo-; y una mayor internacionalización en las cadenas globales de valor. Éstos emergen como requisitos para evitar la saturación del mercado local y mejorar la competitividad internacional sobre la base del desarrollo nacional.

\section{Bibliografía}

ARGENTINA. MECON - Ministerio de Economía. Informes de cadenas de valor. Maquinaria agrícola, año 1, n. 8, 2016.

AROCENA, R.; SUTZ, R. Understanding underdevelopment today: new perspectives on NSI. 2001. Text displayed in The First Globelics Conference: Innovation Systems and Development Strategies for the Third Millennium, Plenary Session 3: National innovation systems and development, Rio de Janeiro, 2001. 
BARLETTA, F.; ROBERT, V.; YOGUEL, G. Complementariedades de conocimiento, estrategias de conectividad e innovación en firmas industriales argentinas. Revista de Economía Política de Buenos Aires, v. 6, n. 11, p. 49-80, 2012.

BELL, M.; ALBU, M. Knowledge systems and technological dynamism in industrial clusters in developing countries. World Development, v. 27, n. 9, p. 1715-1734, 1999.

BELL, M.; PAVITT, K. Technological Accumulation and Industrial Growth: Contrasts Between Developed and Developing Countries. Industrial and Corporate Change, v. 2, n. 2, p. 157-210, 1993.

BELL, M.; PAVITT, K. The development of technological capabilities. In: HAQUE, I. (ed.). Trade, technology and international competitiveness. Washington, D.C.: The World Bank, 1995. p. 60-101.

BISANG, R.; ANLLÓ, G.; CAMPI, M. Políticas tecnológicas para la innovación: la producción agrícola argentina. Santiago de Chile: Cieplan, 2015.

COHEN, W.; LEVINTHAL, D. Absorptive Capacity: A New Perspective on Learning and Innovation. Administrative Science Quarterly, v. 35, n. 1, p. 128-152, 1990. (Special Issue: Technology, Organizations, and Innovation).

DAHLMAN, C.; ROSS-LARSEN, B.; WESTPHAL, L.E. Managing Technological Development: industrializing countries. World Development, v. 15, n. 6, p. 759-775, 1987.

DAHLMAN, C.; WESTPHAL, L.E. Technological Effort in Industrial Development. An Interpretative Survey of Recent Research. In: STEWART, F.; JAMES, J. (ed.). The Economics of New Technology in Developing Countries. London: Frances Pinter, 1982. p. 105-137.

DANTAS, E.; BELL, M. Latecomer firms and the emergence and development of knowledge networks: The case of Petrobras in Brazil. Research Policy, v. 38, n. 5, p. 829-844, 2009.

DANTAS, E.; BELL, M. The Co-Evolution of Firm-Centered Knowledge Networks and Capabilities in Late Industrializing Countries: The Case of Petrobras in the Offshore Oil Innovation System in Brazil. World Development, v. 39, n. 9, p. 1570-1591, 2011.

DUTRENIT, G. Reflexiones sobre la metodología de estudio de caso para analizar los procesos de aprendizaje en las firmas. In: FLORES SALGADO, J.; TIRADO JIMÉNEZ, R. (ed.). Economía industrial y agrícola en México ante la apertura. México DF: Producción económica, 2001. p. 115-134.

DUTRÉNIT, G. Building Technological Capabilities in Latecomer Firms: Review Essay. Science, Technology and Society, v. 9, n. 2, p. 209-241, 2004.

DUTRENIT, G.; ARZA, V. Features of interactions between public research organizations and industry in Latin America: the perspective of researchers and firms. In: ALBUQUERQUE, 
E.; SUZIGAN, W; KRUSS, G.; LEE, K. (ed.). Developing National Systems Of Innovation: University-Industry Interactions in the Global South. Cheltenham: Edward Elgar Publishing, 2015. p. 164-193.

EDQUIST, C. Striving Towards a Holistic Innovation Policy in European Countries - But Linearity Still Prevails!. Lund University, CIRCLE, 2014. (Papers in Innovation Studies, n. 2014/22).

ERBES, A.; ROBERT, V.; YOGUEL, G. Capacities, innovation and feedbacks in production networks in Argentina. Economics of Innovation and New Technology, v. 19, n. 8, p. 719$741,2010$.

FIGUEIREDO, P.N. Discontinuous innovation capability accumulation in latecomer natural resource-processing firms. Technological Forecasting y Social Change, v. 77, n. 7, p. 1090-1108, 2010.

FREEMAN, C.; PÉREZ, C. Structural crises of adjustment: business cycles and investment behavior. In: DOSI, G.; FREEMAN, C.; NELSON, R.; SILVERBERG, G.; SOETE, L. (ed.). Technical Change and Economics Theory. London: Pinter Publishers, 1988. p. 38-66.

GIULIANI, E.; ARZA, V. What drives the formation of 'valuable' university-industry linkages? Insights from the wine industry. Research Policy, v. 38, n. 6, p. 906-921, 2009.

GIULIANI, E.; BELL, M. The micro-determinants of meso-level learning and innovation: evidence from a Chilean wine cluster. Research Policy, v. 34, n. 1, p. 47-68, 2005.

KATZ, J. Domestic Technological Innovations and Dynamic Comparative Advantage: Further Reflections on a Comparative Case-Study Program. Journal of Development Studies, v. 16, n. 1-2, p. 13-38, 1984.

KLERKX, L.; GILDEMACHER, P.R. The role of innovation brokers in agricultural innovation systems. In: WORLD BANK. Agricultural innovation systems: an investment sourcebook. Washington, DC: World Bank, 2012. Module 3. p. 211-230.

LALL, S. Learning to Industrialize: The Acquisition of Technological Capability by India. London: Macmillan Press, 1987.

LALL, S. Technological Capabilities and Industrialization. World Development, v. 20, n. 2, p. 165-186, 1992.

LAVARELLO, P.; SILVA, D.; LANGARD, F. Transferencia de tecnología, tramas locales y cadenas globales de valor: trayectorias heterogenias en la industria de la maquinaria agrícola argentina. Innovación RICEC, v. 2, n. 1, p.1-17, 2010.

LIM, C.; LEE, K. Technological regimes, catching-up and leapfrogging: findings from the Korean industries. Res. Policy, v. 30, n. 3, p. 459-483, 2001. 
LÓPEZ, A. Las evaluaciones de programas públicos de apoyo al fomento y desarrollo de la tecnología y la innovación en el sector productivo en América Latina. Una revisión crítica. Washington, DC: Banco Interamericano de Desarrollo, 2009.

LUNDVALL, B. National systems of innovation. Towards a theory of innovation and interactive learning. London: Pinter Publishers, 1992.

MALERBA, F.; ORSENIGO, L. Knowledge, Innovative Activities and Industrial Evolution. Industrial and Corporate Change, v. 9, n. 2, p. 289-313, 2000.

MOCHI, S. Evolución de las capacidades tecnológicas, los vínculos territoriales y las políticas de innovación. El caso de empresas argentinas de maquinaria agrícola. 2017. 247 p. Tesis (Doctoral en Economía y Gestión de la Innovación) - Universidad Autónoma de Madrid, Madrid, 2017.

NELSON, R.; WINTER, S. An Evolutionary Theory of Economic Change. Cambridge: The Harvard University Press, 1982.

TEECE, D.J.; PISANO, G. The dynamic capabilities of firms: an introduction. Industrial and Corporate Change, v. 3, n. 3, p. 537-556, 1994.

VAN LENTE, H.; HEKKERT, M.; SMITS, R.; VAN WAVEREN, B. Roles of systemic intermediaries in transition processes. International Journal of Innovation Management, v. 7, n. 3, p. 1-33, 2003.

VÁZQUEZ BARQUERO, A. Los territorios innovadores, espacios estratégicos del desarrollo. En: CURBELO, J.L.; PARRILLI, M.D.; ALBURQUERQUE, F. (coord.). Territorios innovadores y competitivos. Madrid: Marcial Pons Ediciones Jurídicas y Sociales S.A., 2011. p. $75-88$.

YIN, R. Case Study Research. Design and Methods. London: SAGE Publications, 2003

Esta artículo fue licenciado bajo CC-BY Creative Commons 4.0 Brazil License 